\title{
A COST-EFFECTIVE ANALYSIS OF TIOTROPIUM WITH FORMOTEROL AND BUDESONIDE WITH FORMOTEROL BASED ON EFFICACY AND QUALITY OF LIFE IN CHRONIC OBSTRUCTIVE PULMONARY DISEASE PATIENTS
}

\author{
KAMESWARI GARNEPUDI*, IVATURI SHRAVANTHI, KEERTHANA SIVAKUMAR, MAITHILI SHARMA M, \\ KURAKULA MANASA
}

\author{
Department of Pharmacy Practice, Malla Reddy College of Pharmacy, Malla Reddy Hospital, Suraram, Hyderabad India. \\ Email:kameswari888@gmail.com
}

Received: 20 June 2018, Revised and Accepted: 20 July 2018

\begin{abstract}
Objectives: The primary objective of the study was to conduct the cost-effective analysis of tiotropium with formoterol versus budesonide with formoterol in the management of Stage-I chronic obstructive pulmonary disease (COPD) based on efficacy and quality of life (QoL). The study also aims to analyze the improvement of the QoL through pulmonary rehabilitation. The secondary objective was to evaluate the incidence of depression and anxiety in COPD patients.
\end{abstract}

Methods: A prospective interventional study, with a sample size of 74 patients diagnosed with COPD Stage-I was conducted for 6 months. The study population was divided based on simple randomization into two main groups, one receiving tiotropium with formoterol and the other receiving budesonide with formoterol. Based on spirometry, their pulmonary function test (PFT) was recorded. The patients QoL was recorded using the WHOQoL-BREF questionnaire.

Results: Data of 74 patients were collected for both the zero-degree and first-degree follow-up. The patients demonstrated good compliance with the transinhaler of the prescribed drugs. A significant improvement after providing pulmonary rehabilitation in PFT, i.e., forced expiratory volume1/ forced vital capacity values $\left(\mathrm{p}=0.000^{* *}\right)$ and the WHOQoL scoring $\left(P=0.001^{* *}\right)$ was observed in patients receiving tiotropium with formoterol. Tiotropium with formoterol was found to be more cost-effective treatment than budesonide with formoterol.

Conclusion: The study showed that transinhalation of $9 \mathrm{mcg} / 12 \mathrm{mcg}$ tiotropium/formoterol once a day is a better cost-effective treatment than $200 \mathrm{mcg} / 6 \mathrm{mcg}$ transinhalation of budesonide/formoterol twice a day.

Keywords: Chronic obstructive pulmonary disease, Tiotropium, Budesonide, Formoterol, Pulmonary function test, Forced expiratory volume 1/ Forced vital capacity, Pulmonary rehabilitation.

(C) 2018 The Authors. Published by Innovare Academic Sciences Pvt Ltd. This is an open access article under the CC BY license (http://creativecommons. org/licenses/by/4. 0/) DOI: http://dx.doi.org/10.22159/ajpcr.2018.v11i11.27991

\section{INTRODUCTION}

Chronic obstructive pulmonary disease (COPD) is the leading reason for morbidity and mortality of patients suffering from obstructive lung disease in the world, and there has been a rise in the number of patients suffering from this condition crossing previously thought age and gender boundaries. The major cause of COPD is smoking. The proportion of non-smokers clinically diagnosed with COPD is over $10 \%$ with women contributing to the majority in developing countries such as India, where exposure to biomass fuels in an enclosed space is an important cause [1].

COPD is an important cause of chronic disability, thereby showing a great impact on the quality of life (QoL) of the patients, especially in the work life. Therefore, the management of the patient should focus on improving the overall health of the patient and also prevent acute exacerbations and subsequent hospitalization to minimize the economic burden on the patient. This can be achieved by simplifying management and improving adherence to prescribed therapy by reducing the dose frequency to the minimum necessary to maintain disease control [2]. Recent guidelines such as GOLD have established that combination therapy is more beneficial in the management of Stage-I COPD [3].

Being a chronic condition, COPD takes its toll on the psychological health of the patient. Psychological complications such as depression and anxiety are highly prevalent and often go undiagnosed and untreated in COPD patients. Since symptoms of depression and anxiety reduce the QoL in these patients, counseling, and treatments aimed at improving mental health may improve their QOL $[4,5]$.

The primary objective of the study was to conduct cost-effective analysis of tiotropium with formoterol versus budesonide with formoterol in the management of Stage-I COPD based on efficacy and QoL. The study also aims to analyze the improvement of the QoL through pulmonary rehabilitation. This includes counseling the patient on medication regimens, usage and handling of MDI, pulmonary exercises, and dietary recommendations. The secondary objective was to evaluate the incidence of depression and anxiety in COPD patients.

\section{METHODS}

The study was conducted in Malla Reddy Hospital, a tertiary care rural hospital located in Hyderabad, Telangana, from December 2015 to August 2016. This is a prospective interventional study. Patients diagnosed with Stage-I COPD and above 21 years of age were included in the study. The reason for choosing patients above 21 years of age was to ascertain the significance of non-smoking factors in the contribution of COPD, especially among women. Key exclusion criteria were asthma, pulmonary T.B., and the presence of a coexisting illness that could preclude participation in the study or interfere with the study results. QoL was analyzed through the WHOQoL-BREF questionnaire. Patient health questionnaire (PHQ)-9 and Zung scales were used to assess 
Table 1: Comparison of PFT-FEV1/FVC values in study population

\begin{tabular}{|c|c|c|c|c|c|c|c|c|c|c|c|c|c|c|c|}
\hline \multirow{3}{*}{$\begin{array}{l}\text { FEV1/FVC } \\
\text { Tiffeneau-Pinelli } \\
\text { index (\%) }\end{array}$} & \multicolumn{15}{|c|}{ Group } \\
\hline & \multicolumn{7}{|c|}{ Budamate } & \multicolumn{7}{|c|}{ Tiomate } & \multirow[t]{2}{*}{$p$ value } \\
\hline & $\mathbf{n}$ & Minimum & Maximum & Mean & SD & Median & IQR & $\mathbf{n}$ & Minimum & Maximum & Mean & SD & Median & IQR & \\
\hline FEV1/FVC-1 & 37 & 64 & 70 & 67.57 & 1.365 & 68 & 2 & 37 & 62 & 70 & 67.16 & 1.537 & 69 & 2 & 0.000 \\
\hline FEV1/FVC-2 & 37 & 75 & 85 & 79.86 & 1.719 & 80 & 2 & 37 & 84 & 98 & 89.49 & 3.805 & 89 & 3 & \\
\hline
\end{tabular}

FEV1/FVC-1 - baseline scores, FEV1/FVC-2 - follow-up scores. Mann-Whitney U-test was performed using SPSS 20 version. A significant improvement in FEV1/FVC values up to $89 \%$ has been recorded in patients receiving tiomate $(\mathrm{p}=0.000)^{* *}$. Improvement up to $79 \% \mathrm{FEV} 1 / \mathrm{FVC}$ values has been recorded in patients receiving budamate, PFT: Pulmonary function test, FEV1/FVC: Forced expiratory volume 1/forced vital capacity, QoL: Quality of life

Table 2: Comparison of the WHOQoL score of baseline and follow-up data in the study population

\begin{tabular}{|c|c|c|c|c|c|c|c|c|c|c|c|c|c|c|c|}
\hline \multirow[t]{3}{*}{ WHOQOL domains } & \multicolumn{15}{|c|}{ Group } \\
\hline & \multicolumn{7}{|c|}{ Budamate } & \multicolumn{7}{|c|}{ Tiomate } & \multirow[t]{2}{*}{ p value } \\
\hline & $\mathbf{n}$ & Minimum & Maximum & Mean & SD & Median & IQR & $\mathbf{n}$ & Minimum & Maximum & Mean & SD & Median & IQR & \\
\hline WHO-1D1 & 37 & 38 & 63 & 51.38 & 7.829 & 50 & 7 & 37 & 25 & 69 & 46.3 & 9.894 & 44 & 12 & 0.000 \\
\hline WHO-2D1 & 37 & 44 & 69 & 57.11 & 7.062 & 56 & 13 & 37 & 44 & 81 & 59.14 & 9.872 & 63 & 16 & \\
\hline WHO-1D2 & 37 & 31 & 63 & 46.76 & 7.897 & 44 & 6 & 37 & 25 & 88 & 43.03 & 13.85 & 44 & 16 & 0.02 \\
\hline WHO-1D2 & 37 & 19 & 63 & 51.19 & 8.205 & 56 & 12 & 37 & 44 & 94 & 50.78 & 10.55 & 44 & 12 & \\
\hline WHO-1D3 & 37 & 25 & 75 & 56.19 & 12.83 & 56 & 16 & 37 & 19 & 94 & 51.84 & 16.54 & 50 & 12 & 0.000 \\
\hline WHO-2D3 & 37 & 31 & 75 & 57.24 & 13.97 & 50 & 25 & 37 & 31 & 94 & 60.76 & 14.27 & 56 & 19 & \\
\hline WHO-1D4 & 37 & 44 & 75 & 61.19 & 10.05 & 63 & 19 & 37 & 25 & 69 & 55.03 & 9.397 & 56 & 13 & 0.001 \\
\hline WHO-2D4 & 37 & 50 & 75 & 62.27 & 9.91 & 63 & 25 & 37 & 38 & 94 & 61.51 & 9.045 & 63 & 13 & \\
\hline
\end{tabular}

WHO-1 represents baseline score, WHO-2 represents follow-up score. D1 - physical aspect, D2 - psychological aspect, D3 - social aspect, D4 - environmental aspect. Mann-Whitney U-test was performed using SPSS 20 version. The improvement of patient's QoL receiving therapies was recorded using the WHOQoL-BREF scale which has four domains and each domain's scores were divided into five subgroups with CI of 20 points. A significant improvement of 59.14 ( $p=0.000$ ) and 60.75 ( $p=0.000$ ) in the physical health and social aspect has been observed, respectively, in patients receiving tiomate when compared to budamate receiving group. Budamate showed improvement in psychological and environmental aspects of the QOL scale over the other group, PFT: Pulmonary function test, QoL: Quality of life

Table 3: Cost-effective analysis between tiomate and budamate based on FEV1/FVC values and QoL score

\begin{tabular}{|c|c|c|c|c|c|c|c|c|c|}
\hline Drug & Dose & $\begin{array}{l}\text { Dose } \\
\text { regimen }\end{array}$ & MDI & Price (Rs) & $\begin{array}{l}\text { Price per } \\
\text { day (Rs) }\end{array}$ & $\begin{array}{l}\text { Avg. follow-up } \\
\text { PFT (FEV1/FVC-2) }\end{array}$ & $\begin{array}{l}\text { Cost-effective } \\
\text { ratio -PFT }\end{array}$ & $\begin{array}{l}\text { Avg. WHOQoL } \\
\text { follow-up score }\end{array}$ & $\begin{array}{l}\text { Cost-effective } \\
\text { ratio-QoL }\end{array}$ \\
\hline Tiomate & $9 \mathrm{mcg}$ & Once a day & 180 (180 days) & 446 & 2.47 & 89.49 & 0.027 & 57.29 & 0.043 \\
\hline Budamate & $200 \mathrm{mcg}$ & Twice a day & 120 (60 days) & 338 & 5.63 & 79.86 & 0.0704 & 56.95 & 0.098 \\
\hline
\end{tabular}

PFT: Pulmonary function test, FEV1/FVC: Forced expiratory volume 1/forced vital capacity, QoL: Quality of life

COPD-associated depression and anxiety, respectively. Pulmonary rehabilitation was provided with the help of a patient information leaflet in the local language. Ethical committee approval was taken from the Institutional Human Ethics Committee. Patient consent was obtained after explaining the study, and the informed consent form was translated into the local language for the convenience of the patients.

The drugs administered were - tiomate: Tiotropium $(9 \mathrm{mcg})+$ formoterol $(12 \mathrm{mcg}) /$ day and budamate: Budesonide $(200 \mathrm{mcg})+$ formoterol $(6 \mathrm{mcg}))$ /day. Both the brands were manufactured by Lupin Laboratories to nullify manufacturer's variance.

Manufacturer details - Lupin Laboratories, Mumbai, India.

\section{Study procedure}

Patients were selected based on inclusion criteria and exclusion criteria after obtaining the consent from the patients. The patients were randomized into two groups based on the drug administered - tiomate group and budamate group. Initially, pulmonary function test (PFT) was done to assess the lung capacity of the patients followed by scoring of the WHOQoL-BREF questionnaire to assess the QoL, PHQ-9 scale for depression, and Zung self-assessment scale for anxiety. Then, pulmonary rehabilitation was provided to the patients. The patients' PFT values, as well as QoL, were reassessed after 4 weeks to evaluate the improvement in efficacy and QoL. The patients were also assessed for the improvement in depression and anxiety after 4 weeks through the PHQ-9 and Zung scale, respectively. Statistical evaluation of data was done.

\section{Statistical analysis of data}

- The PFT - forced expiratory volume 1/forced vital capacity (FEV1/ FVC) values and the WHOQoL-BREF score were analyzed by MannWhitney U-test using SPSS 20 version to observe the efficacy and QoL in tiomate and budamate groups.

- Correlations were done by Epi Info software.

\section{RESULTS}

A total of 100 cases were collected, of which 26 patients dropped out and 74 patients were included in the study. According to simple randomization, 37 received tiomate and 37 received budamate. Majority of the patients fall in the age group of 46-65 years of age and the least recorded age was 26 years. The number of male patients contributes to the majority of the patients recruited for the study. Male-to-female ratio was found to be 4.28:1. Smoking was found to be the major cause for COPD in this study while $26 \%$ of the population fell under non-smoking category. This category subsumes passive smoking and biomass fuel exposure and women were in higher numbers in this group. Smoker-tonon-smoker ratio was found to be $3.62: 1$.

Patients with Stage-I COPD (FEV1/FVC $\geq 60-<70 \%$ ) were included in the study. Two patients were found to have as low as $62-64 \%$ FEV1/ FVC values in each group. Majority of the patients had FEV1/FVC in the range of $68-72 \%$ in budamate group initially. During follow-up, $52 \%$ of the patients receiving budamate showed improvement in the range of $80-84 \%$ FEV1/FVC. The baseline readings showed that $77 \%$ of the patients randomized to receive tiomate were found to have $68-70 \%$ 
Table 4: Incidence of depression in tiomate and budamate study group based on PHQ-9 scale

\begin{tabular}{|c|c|c|c|c|}
\hline Depression - & $\begin{array}{l}\text { Number of } \\
\text { patients -baseline } \\
\text { (tiomate) }\end{array}$ & $\begin{array}{l}\text { Number of } \\
\text { patients -follow-up } \\
\text { (tiomate) }\end{array}$ & $\begin{array}{l}\text { Number of } \\
\text { patients -baseline } \\
\text { (budamate) }\end{array}$ & $\begin{array}{l}\text { Number of } \\
\text { patients -follow-up } \\
\text { (budamate) }\end{array}$ \\
\hline No depression & 30 & 30 & 33 & 33 \\
\hline Minimal depression & 0 & 0 & 0 & 0 \\
\hline Mild depression & 0 & 4 & 0 & 2 \\
\hline Moderate depression & 2 & 1 & 2 & 2 \\
\hline Moderately severe depression & 5 & 2 & 2 & 0 \\
\hline
\end{tabular}

PHQ: Patient health questionnaire

Table 5: Incidence of anxiety in both tiomate and budamate receiving study subjects based on Zung scale

\begin{tabular}{lllll}
\hline Anxiety & Baseline-tiomate & Baseline-budamate & Follow-up - tiomate & Follow-up -budamate \\
\hline Yes & 6 & 6 & 6 & 6 \\
No & 31 & 31 & 31 & 31 \\
Total & 37 & 37 & 37 & 37 \\
\hline
\end{tabular}

Table 6: Correlations between various aspects of the study and PFT

\begin{tabular}{lll}
\hline Correlation & Correlation coefficient (R) & $\mathbf{R}^{2}$ \\
\hline Number of cigarettes/PFT & 0.0312 & 0.0234 \\
Age/PFT & -0.17 & 0.0468380 \\
PFT/domain 1 (physical aspect) & 0.216421 & 0.002596 \\
PFT/domain 2 (psychological aspect)/PFT & 0.050955 & 0.002596412 \\
PFT/domain 3 (social relationships aspect)/PFT & 0.307555 & 0.098628 \\
PFT/domain 4 (environment aspect)/PFT & 0.09274824 \\
\hline
\end{tabular}

PFT: Pulmonary function test

FEV1/FVC. During follow-up, $73 \%$ of patients randomized to receive tiomate were found to have improved $\mathrm{FEV}_{1} / \mathrm{FVC}(85-89 \%)$ values (Tables 1 and 2).

- The incremental cost-effective ratio (ICER) of tiomate and budamate based on their PFT is -0.32 , resulting in tiomate being the costeffective treatment in the patients.

- The ICER of tiomate and budamate is -9.2 , and no significant superiority is seen between two drugs based on QoL improvement in the patients (Table 3 ).

Five of 37 study populations were recorded to have moderately severe depression. Majority of the recruited patients were recorded to have no depression at all. Follow-up after pulmonary rehabilitation showed a substantial improvement in patients with moderate depression and moderately severe depression. No patient continued to have moderately severe depression during follow-up after patient counseling (Table 4).

Six patients each were recorded to have anxiety in tiomate and budamate receiving groups (Table 5).

Karl Pearson's correlation was applied to find correlations between various factors of the study. A negative correlation was found between number of cigarettes and age versus PFT. A positive relation was found between all the four domains of the WHOQoL scale and PFT (Table 6).

\section{DISCUSSION}

A total of 100 patients were recruited for the current study, of which 26 dropped out and 74 remained in the study. The study participants were diagnosed with Stage-I COPD (FEV1/FVC $=>60-<70 \%$ ). Demographic data were collected based on age, gender, smoker, and non-smoker categories. Correlations between age versus PFT, gender versus PFT, and PFT versus each domain of QoL were also done. Similar epidemiology studies were reported by Jindal et al. [6] who performed a multicentric study on the epidemiology of COPD and its relationship with tobacco smoking and environmental tobacco smoke exposure.
Their male-to-female ratio was found to be $1.56: 1$ and smoker-tonon-smoker ratio $2.65: 1$. The current study recorded predominantly male smokers subjects putting general population men with smoking habits at higher odds to develop COPD. Male-to-female ratio among the recruited subjects was recorded to be 4.28:1 and smoker-to-nonsmoker ratio was found to be 3.62:1. Most of the recruited subjects were under the age group of 46-55 years. A negative correlation was found between number of cigarettes versus PFT $(-0.17)$ and age versus PFT $(-0.15)$. A positive correlation was found between PFT and all the four domains of the WHOQoL.

Now, the patients were randomly given tiomate or budamate. They were assessed for the PFT by spirometry. A similar trial was done by Perng et al. [7] to evaluate additive effects of tiotropium in COPD patients treated with long-acting $\beta_{2}$ agonist and corticosteroids where tiotropium significantly improved FVC, $\mathrm{FEV}_{1}$, and inspiratory capacity (IC). Their study showed that after tiotropium withdrawal FVC, FEV and IC decreased markedly. In the current study, significant increases in $\mathrm{FEV}_{1} / \mathrm{FVC}$, from $68 \%$ to $89 \%$, values were seen in the tiomate study group.

Now, the patients were assessed for the status of their QoL based on the WHOQoL-BREF questionnaire. Based on the score, patients were given pulmonary rehabilitation on the medication regimen, how to use MDI, cleaning of MDI, pulmonary exercises, and appropriate diet that can be followed at home. This is similar to a study conducted by Wijkstra et al. [8] on long-term benefits of rehabilitation at home on QoL and exercise tolerance in patients with COPD. Their study concluded that rehabilitation at home for 3 months followed by once monthly physiotherapy sessions improves QoL over 18 months. In the current study, a significant improvement in the QoL in the study population was seen better in the tiomate study group than budamate group after 4 weeks of pulmonary rehabilitation.

Finally, cost-effective analysis between treatments with tiomate versus budamate was done considering their cost of treatment per day and health outcomes based on PFT - FEV1/FVC and QOL. 
This was done based on work done by Mittmann et al. [9], on the cost-effectiveness of budesonide or formoterol added to tiotropium bromide versus placebo added to tiotropium bromide in patients with COPD in Australian, Canadian, and Swedish health-care perspectives. Budesonide or formoterol added to tiotropium was the dominant strategy compared with placebo added to tiotropium in their trial. In the current comparative study, both CER and ICER of tiotropium with formoterol strategy were found to be less than budesonide with formoterol in both categories of PFT and QOL improvement.

The PHQ-9 scale was administered to record the incidence of depression in both groups. This was done by taking into consideration the study done by Schane et al. [10], on the prevalence and risk factors for depressive symptoms in persons with COPD. They recorded an incidence of depression in 97 patients with severe COPD (FEV1/FVC $<40 \%$ ). In the current study, seven in the tiomate receiving group and four in the budamate receiving group were recorded to have depression (FEV1/FVC $<70 \%>60 \%$ ). The follow-up PHQ-9 scores also showed the improvement in depression patients to an extent after 4 weeks of therapy and pulmonary rehabilitation.

Zung self-assessment scale for anxiety was administered to patients that presented anxiety symptoms. The incidence of anxiety associated with COPD was recorded. This is similar to study done by Withers et al. [11], on anxiety and depression in severe COPD. Levels of anxiety and depression were high in a significant minority of their group of patients with severe COPD and were significantly improved by pulmonary rehabilitation. They recorded 18 patients to have anxiety on HAD scale. Similarly, in the current study, 12 patients were found to have COPD-associated anxiety on the Zung scale.

\section{CONCLUSION}

In the present study, administering the combination of tiotropium and formoterol (tiomate) or budesonide and formoterol (budamate) through transinhalation, per day treatment, targets either bronchodilation or immune suppression, or both. Tiomate was found to be cost-effective and efficacious when compared to budamate.

Intervention with pulmonary rehabilitation also reflected a substantial improvement in the QoL and patients morbidity. Patients demonstrated good compliance with both administration of prescribed medication and dietary and exercise recommendations.

Therefore, prescribing patients diagnosed with Stage-I COPD the combination of tiotropium with formoterol at the dose of $9 \mathrm{mcg}+$ $12 \mathrm{mcg} /$ day along with pulmonary rehabilitation helped in improving the PFT - FEV1/FVC status.

Further, intense studies are required to confirm the quality of therapeuticity of the drugs in maintaining the normalcy of health in the long run of COPD patients.

\section{ACKNOWLEDGMENTS}

We would like to express our gratitude to Dr. Sai Vittal for his invaluable guidance and also thank the hospital staff and patients of Malla Reddy Hospital, for their support.

\section{AUTHORS' CONTRIBUTION}

All the authors have contributed to some or all parts of the study.

\section{CONFLICTS OF INTEREST}

No conflicts of interest by the authors.

\section{REFERENCES}

1. Khan PA, Sujala A, Nousheen S, Fatima AF, Ala HB, Reddy P. A comparative evaluation of the efficacy of triple drug therapy with dual drug therapy in COPD patients. Int $\mathrm{J}$ Pharm Pharm Sci 2018;10:105-9.

2. Barnes PJ. Chronic obstructive pulmonary disease: A growing but neglected global epidemic. PLoS Med 2007;4:e112.

3. Global Initiative for Chronic Obstructive Lung Disease. Global Strategy For The Diagnosis, Management, And Prevention Of Chronic Obstructive Pulmonary Disease.; 2016. Available from:https:/www.goldcopd.org/global-strategy-diagnosis-ma nagement-prevention-copd-2016.

4. Altaf M, Masood QM, Ahmed TZ, Ilyaz M, Basha SA. Health related quality of life assessment using St. George's respiratory questionnaire in chronic obstructive pulmonary disease patients on combined inhaled corticosteroids and bronchodilators. Int J Pharm Pharm Sci 2016;8:445-9

5. Paz-Díaz H, Montes de Oca M, López JM, Celli BR. Pulmonary rehabilitation improves depression, anxiety, dyspnea and health status in patients with COPD. Am J Phys Med Rehabil 2007;86:30-6.

6. Jindal SK, Aggarwal AN, Chaudhry K, Chhabra SK, D'Souza GA, Gupta D, et al. A multicentric study on epidemiology of chronic obstructive pulmonary disease and its relationship with tobacco smoking and environmental tobacco smoke exposure. Indian J Chest Dis Allied Sci 2006;48:23-9.

7. Perng DW, Wu CC, Su KC, Lee YC, Perng RP, Tao CW, et al. Additive benefits of tiotropium in COPD patients treated with long-acting beta agonists and corticosteroids. Respirology 2006;11:598-602.

8. Wijkstra PJ, Ten Vergert EM, van Altena R, Otten V, Kraan J, Postma DS, et al. Long term benefits of rehabilitation at home on quality of life and exercise tolerance in patients with chronic obstructive pulmonary disease. Thorax 1995;50:824-8.

9. Mittmann N, Hernandez P, Mellström C, Brannman L, Welte T. Cost effectiveness of budesonide/formoterol added to tiotropium bromide versus placebo added to tiotropium bromide in patients with chronic obstructive pulmonary disease: Australian, canadian and swedish healthcare perspectives. Pharmacoeconomics 2011;29:403-14.

10. Schane RE, Walter LC, Dinno A, Covinsky KE, Woodruff PG. Prevalence and risk factors for depressive symptoms in persons with chronic obstructive pulmonary disease. J Gen Intern Med 2008;23:1757-62.

11. Withers NJ, Rudkin ST, White RJ. Anxiety and depression in severe chronic obstructive pulmonary disease: The effects of pulmonary rehabilitation. J Cardiopulm Rehabil 1999;19:362-5. 